\title{
Regulation of pre-mRNA splicing in Xenopus oocytes by targeted 2'-O-methylation
}

\author{
JUNHUI GE, ${ }^{1,3}$ HUIMIN LIU, ${ }^{2}$ and YI-TAO YU ${ }^{1}$ \\ ${ }^{1}$ Department of Biochemistry and Biophysics, University of Rochester Medical Center, Rochester, New York 14642, USA \\ ${ }^{2}$ Department of Pathology, Changzheng Hospital, Second Military Medical University, Shanghai 200003, People's Republic of China
}

\begin{abstract}
The 2'-OH group of the branch point adenosine is a key moiety to initiate pre-mRNA splicing. We use RNA-guided RNA modification to target the pre-mRNA branch point adenosine for 2' $-O$-methylation, with the aim of blocking pre-mRNA splicing in vertebrate cells. We show that, under certain conditions, injection of a branch point-specific artificial box C/D RNA into Xenopus oocytes effectively $2^{\prime}$-O-methylates adenovirus pre-mRNA at the target nucleotide. However, 2' $\mathrm{O}$-methylation at the authentic branch point activates a host of cryptic branch points, thus allowing splicing to continue. These cryptic sites are mapped, and mutated. Upon injection, pre-mRNA free of cryptic branch points fails to splice when the branch point-specific box C/D RNA is present. However, 2'-O-methylation at the branch point does not prevent pre-mRNA from being assembled into pre-catalytic spliceosome-like complexes prior to the first chemical step of splicing. Our results demonstrate that RNAguided pre-mRNA modification can occur in the nucleoplasm of vertebrate cells, thus offering a powerful tool for molecular biology research.
\end{abstract}

Keywords: RNA modification; Xenopus oocyte; box C/D guide RNA; branch site; splicing

\section{INTRODUCTION}

pre-mRNA splicing is a post-transcriptional RNA processing reaction by which introns are removed from mRNA precursors (pre-mRNAs) and exons are precisely joined together to form functional mature mRNAs (Staley and Guthrie 1998; Burge et al. 1999; Yu et al. 1999). pre-mRNA splicing occurs via a two-step transesterification reaction pathway (Fig. 1). In the first step, the $2^{\prime}$ hydroxyl group $\left(2^{\prime}-\mathrm{OH}\right)$ of the branch point nucleotide adenosine attacks the phosphate at the $5^{\prime}$ exon-intron junction $\left(5^{\prime}\right.$ splice site), resulting in the cleavage of the phosphodiester bond

\footnotetext{
${ }^{3}$ Present address: Department of Pathology, Changzheng Hospital, Second Military Medical University, 415 Fengyang Road, Shanghai 200003, People's Republic of China.

Reprint requests to: Yi-Tao $\mathrm{Yu}$, Department of Biochemistry and Biophysics, University of Rochester Medical Center, 601 Elmwood Avenue, Rochester, NY 14642, USA; e-mail: yitao_yu@urmc.rochester.edu; fax: (585) 275-6007; Junhui Ge, Department of Pathology, Changzheng Hospital, Second Military Medical University, 415 Fengyang Road, Shanghai 200003, People's Republic of China; e-mail: junhui.ge@hotmail. com; fax: 0086-21-63520020; or Huimin Liu, Department of Pathology, Changzheng Hospital, Second Military Medical University, 415 Fengyang Road, Shanghai 200003, People's Republic of China; e-mail: huimin_liu@ live.com; fax: 0086-21-63520020.

Article published online ahead of print. Article and publication date are at http://www.rnajournal.org/cgi/doi/10.1261/rna.2060210.
}

between the $5^{\prime}$ exon and intron and the concurrent formation of a new $5^{\prime}-2^{\prime}$ phosphodiester bond between the $5^{\prime}$ end of the intron and the branch point adenosine. Thus, a lariat-structured intermediate (lariat intron-3' exon) and a cutoff $5^{\prime}$ exon intermediate are produced. In the second step, the $3^{\prime}-\mathrm{OH}$ group of the cut-off $5^{\prime}$ exon attacks the phosphate at the intron- $3^{\prime}$ exon junction ( $3^{\prime}$ splice site), releasing the lariat intron product and generating the spliced mature mRNA product.

The two chemical reactions occur only after pre-mRNA is assembled into a functional spliceosome, a multi-component complex composed of five small nuclear RNAs (snRNAs $\mathrm{U} 1, \mathrm{U} 2, \mathrm{U} 4, \mathrm{U} 5$, and U6) and a large number of protein factors (Staley and Guthrie 1998; Burge et al. 1999; Yu et al. 1999). During spliceosome assembly, spliceosomal snRNAs and associated protein factors recognize and interact with the consensus sequences in the pre-mRNA, including the $5^{\prime}$ and $3^{\prime}$ splice sites and the branch site sequence, facilitating and specifying the transesterification reactions. The newly assembled spliceosome contains all five spliceosomal snRNAs. However, before the first chemical reaction takes place, the spliceosome undergoes a series of conformational changes (Nilsen 1994). Specifically, U1 and U4 dissociate from the complex, and U2 and U6 form new duplexes that are believed to be part of the catalytic center, allowing the 


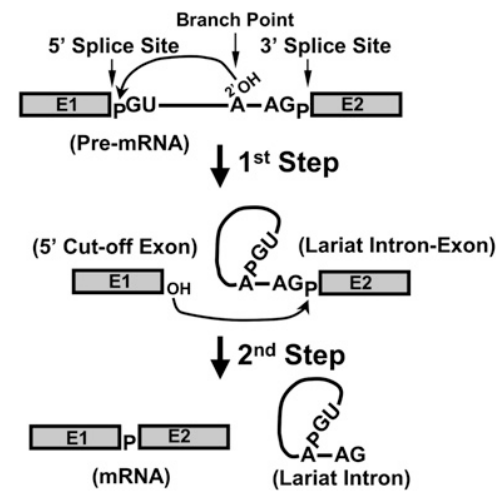

FIGURE 1. Schematic representation of splicing pathway. Two successive transesterification reactions are shown (first and second steps). The $5^{\prime}$ and $3^{\prime}$ splice sites and the branch point adenosine are indicated. Boxes with E1 and E2 represent exon 1 and exon 2, respectively. The line (together with some key nucleotides) denotes the intron.

branch point adenosine to initiate the nucleophilic attack on the phosphate at the $5^{\prime}$ splice site (the first chemical reaction) (Parker et al. 1987; Wu and Manley 1989; Zhuang and Weiner 1989; Newby and Greenbaum 2002). After the first step, the spliceosome undergoes additional conformational changes, leading to the second step.

According to the splicing mechanism, the $2^{\prime}-\mathrm{OH}$ group of the branch point adenosine is a key moiety that initiates the splicing reaction. If the $2^{\prime}-\mathrm{OH}$ group of the branch point adenosine is converted to $2^{\prime}$-OMe (methylated), the splicing of the intron would likely be inhibited and no lariat intron and mature mRNA would be produced. In fact, it has been demonstrated that the branch point lacking the $2^{\prime}-\mathrm{OH}$ group is inactive in initiating the splicing in vitro (Query et al. 1994). Therefore, to silence a gene at the level of pre-mRNA splicing, 2'-O-methylation at the branch point adenosine of pre-mRNA will likely be a very effective approach.

There exists a specific type of snoRNA, namely, box C/D snoRNA, that directs RNA 2'-O-methylation in the cell (Fig. 2; Cavaille et al. 1996; Kiss-Laszlo et al. 1996; Smith and Steitz 1997; Kiss 2002; Yu et al. 2005). Box C/D RNA folds into a unique secondary structure, which is tightly associated with a common set of four core proteins (Fibrillarin, $15.5 \mathrm{kDa}$, Nop56, and Nop58). The two short sequences, one between box $\mathrm{C}$ and box $\mathrm{D}^{\prime}$ and the other between box $\mathrm{C}^{\prime}$ and box $\mathrm{D}$, serve as guides that base-pair with their target RNAs, thereby directing fibrillarin, a methyltransferase, to 2'-O-methylate the residue base-paired to the snoRNA nucleotide precisely 5 nucleotides (nt) upstream of box D (or D') (Fig. 2; Cavaille et al. 1996; Kiss-Laszlo et al. 1996).

Box C/D snoRNAs have been localized to the nucleoli and Cajal bodies, where they naturally direct 2'-O-methylation of rRNAs and snRNAs (Darzacq et al. 2002; Deryusheva and Gall 2009; Tycowski et al. 2009). Interestingly, when expressed in the cell, artificial snoRNAs can also efficiently guide rRNA modifications at target sites (Cavaille et al. 1996; Ni et al. 1997; Liu et al. 2001, 2008; Liu and Fournier 2004).

Besides being localized to the nucleoli and Cajal bodies, snoRNAs appear to be present in the nucleoplasm as well (Liang et al. 2002; Zhao et al. 2002). Consistent with this notion, recent data strongly suggest that modification machinery is dispersed throughout the nucleoplasm (rather than being present exclusively in the nucleolus and Cajal bodies) (Deryusheva and Gall 2009). Along these lines, we recently used this RNA-guided RNA modification scheme to target the branch point nucleotide of a pre-mRNA in Saccharomyces cerevisiae, and successfully inhibited its splicing (Zhao and $\mathrm{Yu}$ 2008).

In this study, we use RNA-guided RNA modification to study pre-mRNA splicing in vertebrate cells. We showed that an artificial box C/D guide RNA, when injected into Xenopus oocytes, targeted pre-mRNA for 2'-O-methylation, thereby blocking splicing. It appears that pre-mRNA containing a $2^{\prime}$-O-methylated branch point was assembled, but was locked into nonproductive precatalytic spliceosome-like complexes.

\section{RESULTS}

\section{An artificial box C/D RNA can target pre-mRNA for 2'-O-methylation}

To investigate whether a branch point adenosine in vertebrate cells could be $2^{\prime}$-O-methylated, thereby inhibiting splicing, we took advantage of the Xenopus oocyte microinjection system, where pre-mRNA splicing and RNA-guided RNA modification occur efficiently and accurately (Yu et al. 1998, 2001). We designed a box C/D guide RNA based on $\mathrm{U} 25$, a naturally occurring box C/D RNA discovered in human and Xenopus cells (Tycowski et al. 1996). All nucleotide sequences were left unchanged except for the short

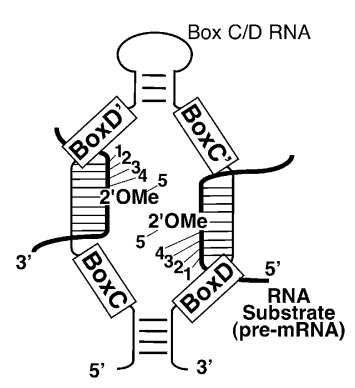

FIGURE 2. Schematic representation of the base-pairing interaction of box C/D snoRNA with its substrate RNA. The thin line represents box C/D snoRNA sequence, and the thick lines depict the substrate RNA. Boxes $C, D^{\prime}, C^{\prime}$, and $\mathrm{D}$ are indicated. The short horizontal lines indicate base-pairing interactions. The target nucleotide, which basepairs with the nucleotide of the box C/D snoRNA precisely $5 \mathrm{nt}$ upstream of box $\mathrm{D}^{\prime}$ or box $\mathrm{D}$, is also indicated $\left(2^{\prime} \mathrm{OMe}\right)$. 
guide sequence located between box $\mathrm{C}$ and box $\mathrm{D}^{\prime}$. The altered box $\mathrm{C} / \mathrm{D}$ guide RNA possessed a new guide sequence targeting the branch point adenosine of the adenovirus premRNA.

We injected the artificial guide RNA into Xenopus oocytes depleted of endogenous U2. (The purpose of using U2-depleted oocytes was to slow down/stop splicing, thus providing sufficient time for the pre-mRNA to be $2^{\prime}$ $O$-methylated). After reconstitution of box C/D guide RNA in the oocytes, adenovirus pre-mRNA containing a single ${ }^{32} \mathrm{P}$ at the branch point adenosine $\left(5^{\prime}\right.$ of the nucleotide) was injected. Upon incubation for more than $4 \mathrm{~h}, \mathrm{U} 2$ snRNA was then injected to trigger splicing. After splicing, RNA was recovered and analyzed on a denaturing gel.

Surprisingly, the result suggested that injection of the artificial box C/D guide RNA targeting the branch point adenosine had little effect on pre-mRNA splicing (Fig. 3A); only a slight reduction of splicing was observed (Fig. 3A, cf. lane 1 and lane 2). Given the fact that pre-mRNA containing a 2'-O-methylated branch point adenosine cannot be spliced, our result raised the possibility that $2^{\prime}$-O-methylation guided by the artificial guide RNA was rather inefficient, leading to a minimal blockage of splicing.

To quantify $2^{\prime}$-O-methylation at the target branch point adenosine, we excised the bands corresponding to the lariat intron and unreacted pre-mRNA. The lariat intron was then debranched with debranching enzymes present in HeLa cell S-100 extract (Ruskin and Green 1985). Debranched lariat and unspliced pre-mRNA were then digested with nuclease P1 and analyzed by thin layer chromatography (TLC). As expected, when a random box $\mathrm{C} / \mathrm{D}$ guide RNA was injected, no 2'-O-methylation was detected at the branch point adenosine (Fig. 3B, lanes 3,4). To our surprise, however, when the artificial box C/D guide RNA targeting the branch point adenosine was present, the branch point was as efficiently $2^{\prime}$-O-methylated in the spliced lariat intron as in the unspliced pre-mRNA (Fig. 3B, cf. lane 2 and lane 1). This result indicated that splicing occurred despite the fact that the branch point was $2^{\prime}$-O-methylated. The only reasonable explanation was that upon $2^{\prime}-O$-methylation at the authentic branch point, other cryptic branch points were activated, leading to active splicing.

\section{A number of sites in the adenovirus pre-mRNA intron can be used as a branch site for splicing}

To determine the branch point nucleotides used in the reaction, we carried out primer-extension analysis using a primer complementary to the last $18 \mathrm{nt}$ of the intron and the nuclear RNA (including the lariat intron and the unspliced pre-mRNA) isolated from oocytes as templates. It is well documented that primer extension will stop $1 \mathrm{nt}$ before the branch point (Ruskin et al. 1984). As shown in Figure 4, a major band corresponding to the authentic branch point was observed when a random guide RNA was
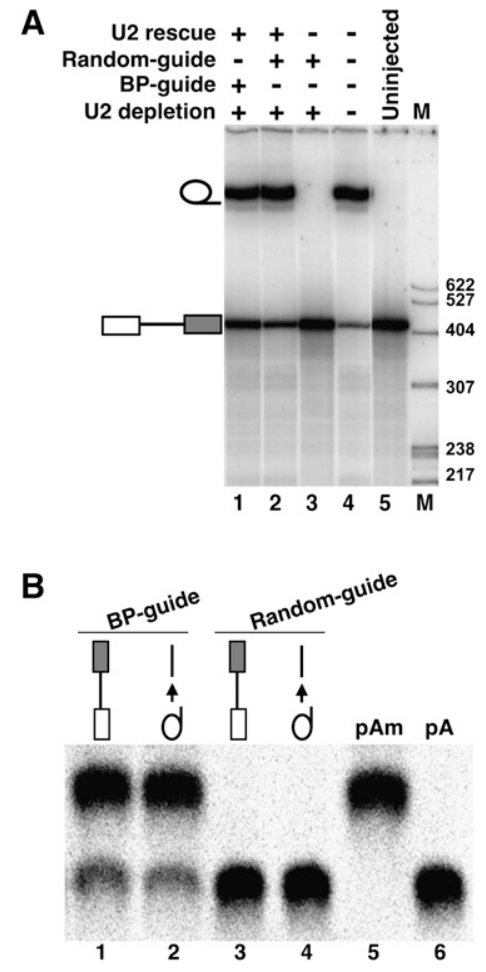

FIGURE 3. Splicing of adenovirus pre-mRNA in Xenopus oocytes. (A) Pre-mRNA containing a single ${ }^{32} \mathrm{P}$ at the branch point adenosine ( $5^{\prime}$ of the nucleotide) was injected into (lane 4) the nuclei of intact Xenopus oocytes or (lanes 1-3) U2-depleted Xenopus oocytes, which had been pre-injected with (lane 4) no guide RNA, (lanes 2,3) a box $\mathrm{C} / \mathrm{D}$ guide RNA containing random guide sequences, or (lane 1 ) a box $\mathrm{C} / \mathrm{D}$ guide RNA targeting the branch point adenosine. Injected oocytes were then supplemented (lanes 1,2) with or (lanes 3,4) without in vitro synthesized U2. (Lane 5) Un-injected pre-mRNA. The positions of pre-mRNA and lariat intron product are also indicated. $(B)$ The lariat intron and unspliced pre-mRNA were recovered from lane 1 of $A$ (lanes 1,2 ) and lane 2 of $A$ (lanes 3,4). After debranching, (lanes 2,4) the debranched intron (released from the lariat structure) as well as (lanes 1,3) the unspliced pre-mRNA were treated with nuclease P1 and analyzed on a TLC plate. (Lane 6) $5^{\prime}\left[{ }^{32} \mathrm{P}\right]-\mathrm{pA}(\mathrm{pA})$ and (lane 5) $2^{\prime}-O$-methylated $5^{\prime}\left[{ }^{32} \mathrm{P}\right]-\mathrm{pA}(\mathrm{pAm})$ were analyzed in parallel.

present (Fig. 4, lane 1), and multiple bands were detected when the artificial guide RNA targeting the authentic branch point was present (Fig. 4, lane 2). All bands were $1 \mathrm{nt}$ before an adenosine (Fig. 4, lane 2), suggesting that these residues (at least some) served as branch points when the authentic branch point was $2^{\prime}$-O-methylated. Interestingly, the major band was shifted, and it corresponded to the adenosine $6 \mathrm{nt}$ upstream of the authentic branch point adenosine. It is conceivable that a large fraction of premRNA was spliced via this major cryptic branch site. Perhaps because of the minimal distance between the two adenosines ( $6 \mathrm{nt}$ apart), the lariat intron products generated via both branch points (the major cryptic and the authentic) migrated to the same position on the gel (Fig. 3A, lane 2).

Given that the authentic adenosine was also used (Fig. 4, lane 2), our results suggested that 2'-O-methylation at this 


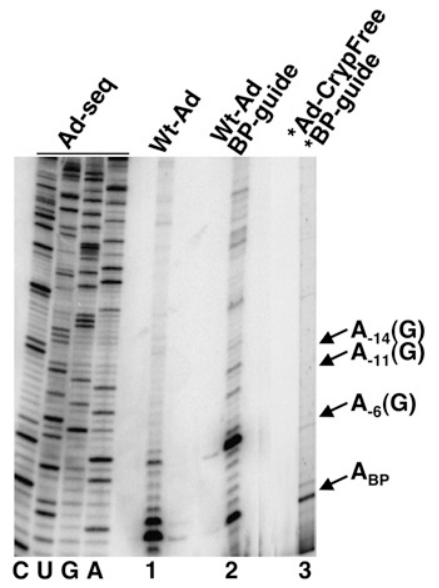

FIGURE 4. Mapping the branch point by primer extension. (Lanes 1,2) Wild-type adenovirus pre-mRNA or (lane 3) mutant adenovirus pre-mRNA (free of cryptic sites) was injected into Xenopus oocytes containing (lane 1) a random box C/D RNA or (lanes 2,3) a box C/D guide RNA targeting the branch point adenosine. After splicing, nuclear RNA was recovered, and primer extension was performed. Primer-extension stops, corresponding to adenosines at the authentic branch point (BP), $6 \mathrm{nt}\left(\mathrm{A}_{-6}\right) 11 \mathrm{nt}\left(\mathrm{A}_{-11}\right)$, and $14 \mathrm{nt}\left(\mathrm{A}_{-14}\right)$ upstream of the authentic branch point, are indicated. A band immediately above $A_{B P}$ in lane 1 was presumably caused by RNA degradation. Guanosines in parentheses $(G)$ indicate three point mutations introduced simultaneously into the pre-mRNA, creating the mutant pre-mRNA free of cryptic branch sites (lane 3, and also see Fig. 5A). Asterisks denote mutant adenovirus pre-mRNA (free of cryptic branch sites) and its respective box C/D guide RNA targeting the branch point of the mutant pre-mRNA.

target site was not $100 \%$; a small fraction of unmodified premRNA permitted splicing via the authentic branch point. This result is consistent with the previous TLC result (Fig. 3B).

\section{2'-O-Methylation targeting the branch point adenosine sufficiently suppresses the splicing of a cryptic site-free pre-mRNA}

To generate a clean pre-mRNA substrate for targeted 2'-Omethylation analysis, we then mutated several major cryptic branch point adenosines (including the one that is located $6 \mathrm{nt}$ upstream of the authentic branch point) (Fig. 4) to guanosines (see Fig. 5A), and the new substrate was tested for splicing (Fig. 5B). In the presence of the branch pointspecific artificial box C/D guide RNA, pre-mRNA splicing levels were markedly lowered (Fig. 5B, lane 1) when compared to the control reaction where a random box C/D guide RNA was present (Fig. 5B, lane 2). RNA bands corresponding to the unspliced pre-mRNA and lariat intron were excised and assayed for modification. As shown in Figure 5C, when the artificial box $\mathrm{C} / \mathrm{D}$ guide RNA targeting the branch point adenosine was present, a large fraction of 2'-O-methylated branch point adenosine was detected in the unspliced pre-mRNA (Fig. 5C, lane 1); importantly, no 2'-O-methylated branch point adenosine was detected in the spliced lariat intron (Fig. 5C, lane 2).
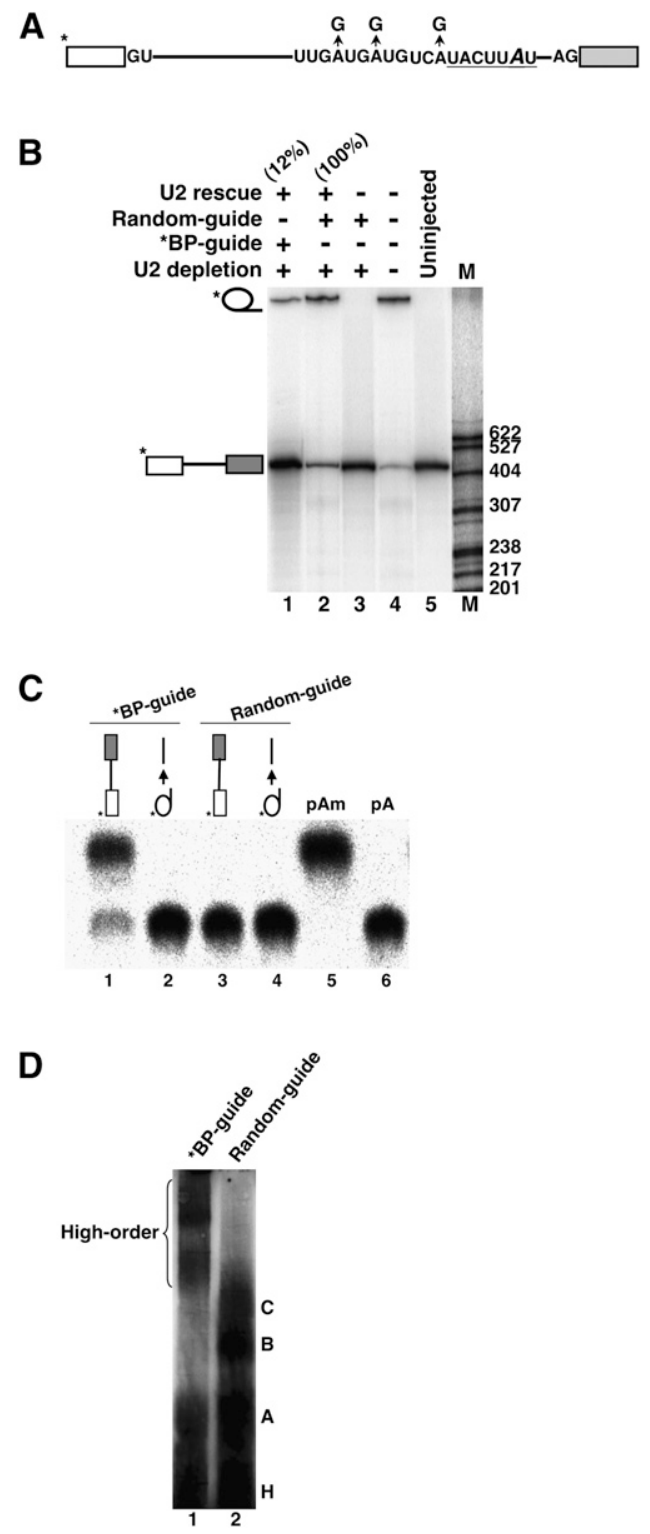

FIGURE 5. Target pre-mRNA 2'-O-methylation for splicing regulation. (A) Mutant adenovirus pre-mRNA free of cryptic branch sites is schematized. Three A-to-G substitutions are indicated. (B) Splicing inhibition by artificial box C/D guide RNA targeting the branch point adenosine. The figure legend is essentially the same as that to Figure 3A. The numbers in parentheses indicate the percentage of splicing that occurred (calculated according to the relative ratio of lariat intron/pre-mRNA in lanes 1 and 2 , with the ratio in lane 2 being set to $100 \%$ ). (C) Quantitation of 2'-O-methylation at the branch point adenosine. The figure legend is identical to that to Figure 3B. Note, no $2^{\prime}$-O-methylated adenosine was detected in lane 2. (D) Native gel analysis. Reactions were carried out exactly as described (see Fig. 5B, lanes 1,2; Fig. 3A, lanes 1,2), except that, after in vitro transcribed U2 was injected, oocytes were incubated for only $10 \mathrm{~min}$. Immediately following the 10-min incubation, nuclei were isolated, broken with loading dye, and directly loaded onto a $4 \%$ native polyacrylamide gel. (Lane 1) Oocytes with a box C/D guide RNA targeting the branch point adenosine; (lane 2) oocytes with a random box $\mathrm{C} / \mathrm{D}$ guide RNA. Complexes H, A, B, and C, as well as high-order complexes, are indicated. Asterisks denote mutant adenovirus pre-mRNA (free of cryptic branch sites), mutant lariat intron, and box C/D guide RNA targeting the branch point of the mutant pre-mRNA. 
Primer extension was also carried out to assess the use of the branch site. As shown in Figure 4, only a single moderately intense band corresponding to the authentic branch point was detected (Fig. 4, lane 3), suggesting that no other sites served as a branch point. The authentic branch point detected here apparently reflected the small fraction of unmodified pre-mRNA (see Fig. 5B, lane 1). Taken together, these results demonstrated that the branch point adenosine can be efficiently targeted for $2^{\prime}-O$-methylation, thereby effectively suppressing pre-mRNA splicing.

\section{Targeted pre-mRNA 2'-O-methylation at the branch point adenosine alters the course of spliceosome assembly}

The pre-mRNA free of cryptic branch sites was also used for spliceosome assembly assay. Radiolabeled pre-mRNA was injected into the nuclei of U2-depleted oocytes containing the branch point-specific box $\mathrm{C} / \mathrm{D}$ guide RNA or a random box C/D RNA. U2 RNA was then injected to reconstitute splicing. Ten minutes later, the nuclei were collected, broken, and directly loaded onto a native gel to reveal splicing complexes.

As shown in Figure 5D, in the presence of a random box $\mathrm{C} / \mathrm{D}$ guide RNA, all splicing complexes, namely, complexes $\mathrm{A}, \mathrm{B}$, and $\mathrm{C}$, were detected (Fig. 5D, lane 2). In contrast, when a box C/D RNA, containing a branch point-specific guide sequence, was injected, we detected only complex A; no active complexes $\mathrm{B}$ and $\mathrm{C}$ were observed. Interestingly, however, some distinct higher-order complexes were detected (Fig. 5D, lane 1).

To further characterize these higher-order complexes, we excised the complexes from the gel, eluted RNA, and performed RT-PCR experiments to detect the presence of snRNAs in these complexes. Interestingly, we detected only U2, U5, and U6 snRNAs; no U1 and U4 snRNAs were present (data not shown). Taken together, these results suggest that pre-mRNA containing a $2^{\prime}$-O-methylated branch point adenosine allows the formation of pre-splicing complex A, in which $\mathrm{U} 2$ base-pairs with the branch site, and allows complex A to be converted into a pre-catalytic spliceosome (complexes B/C lacking U1 and U4) prior to the first step of splicing (Nilsen 1994). The higher-order complexes might represent the first-step-deficient complexes (see Discussion).

\section{Targeted 2'-O-methylation inhibits gene expression when an intron-containing gene (in the form of DNA plasmid) is injected}

In the experiments discussed above, we injected pre-mRNA into Xenopus oocyte nuclei. To test whether our approach could be applied to a more natural setting, we injected the Xenopus oocyte nuclei with T7 polymerase along with a DNA plasmid coding for standard adenovirus pre-mRNA (free of cryptic branch points), expression of which was under the control of the T7 promoter. It is well established that, once injected, T7 polymerase is fully functional in Xenopus oocytes (Altafaj et al. 2006). Thus, we anticipated full production of the adenovirus pre-mRNA transcript in the Xenopus nuclei. Pre-mRNA splicing was tested in the presence or absence of artificial box C/D guide RNA targeting the branch point adenosine.

Northern blotting indicated that adenovirus pre-mRNA spliced very efficiently when a random guide RNA was present (Fig. 6, lane 4). In contrast, when the artificial guide RNA targeting the branch point adenosine was present, splicing was greatly suppressed (Fig. 6, lanes 5,6). Interestingly, we noticed that no pre-mRNA was detected in these experiments, even when splicing was blocked. To verify this observation, we constructed a mutant pre-mRNA in which the $5^{\prime}$ splice site was mutated (from G/GU to G/CG). As expected, injection of this pre-mRNA into the nuclei of oocytes led to no splicing-only unspliced mutant premRNA was readily observed. However, when T7 polymerase and a T7 plasmid containing the same mutant premRNA were injected, no pre-mRNA was detected (data not shown). It appeared that the pre-mRNA was either

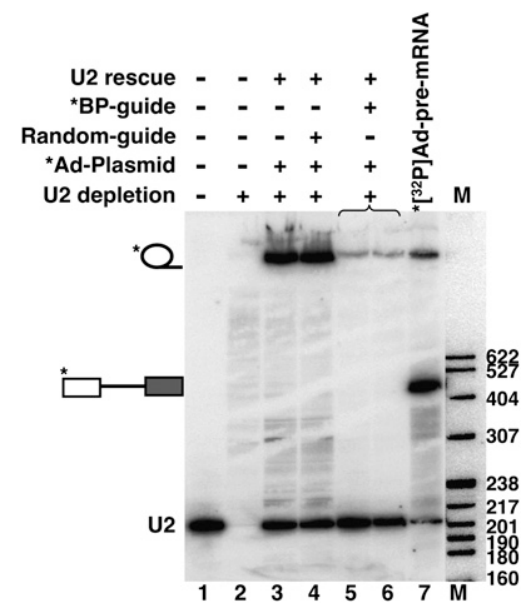

FIGURE 6. Splicing inhibition assay using a T7 plasmid containing an adenovirus pre-mRNA gene (free of cryptic branch sites). (Lanes 2-6) Xenopus oocytes were depleted of endogenous U2 and injected either with (lanes 2,3) no guide RNA, (lane 4) a random box C/D guide RNA, or (lanes 5,6) a box C/D guide RNA targeting the branch point adenosine. The oocytes were then injected either (lanes 3-6) with or (lane 2) without T7 polymerase and a T7 plasmid containing an adenovirus pre-mRNA gene in which the cryptic branch sites were mutated. After an overnight incubation, the oocytes were finally supplemented (lanes 3-6) with or (lane 2) without in vitro transcribed U2. Nuclear RNA was recovered, and Northern analysis was performed with an intron-specific probe and a U2-specific probe. (Lane 1) Oocytes with no injection; (lane 7) radiolabeled pre-mRNA directly injected into intact oocytes; (lanes 5,6) duplicated experiments. Bands corresponding to lariat intron, pre-mRNA, and U2 are indicated. Asterisks denote mutant adenovirus pre-mRNA (free of cryptic branch sites), mutant lariat intron, and box C/D guide RNA targeting the branch point of the mutant pre-mRNA. 
degraded or exported to the cytoplasm in a transcriptiondependent manner. Nonetheless, our results demonstrate that targeted 2'-O-methylation can block pre-mRNA splicing in Xenopus oocytes, regardless of what is injected, premRNA or DNA containing the pre-mRNA gene.

\section{DISCUSSION}

Using the Xenopus oocyte injection system, we have demonstrated that pre-mRNA can be targeted for 2'-Omethylation. When the authentic branch point nucleotide was 2'-O-methylated, this branch point was no longer used; however, for adenovirus pre-mRNA, a number of cryptic branch point nucleotides were activated in response to $2^{\prime}$-O-methylation at the authentic branch point, permitting splicing to occur. For a pre-mRNA free of cryptic branch points, 2'-O-methylation at the authentic branch point adenosine apparently resulted in the formation of nonproductive splicing complexes, which led to splicing failure.

The fact that a number of branch points can be activated (Fig. 4) indicates that the consensus sequence of the vertebrate branch site (YNYURAC, where $\mathrm{N}$ is any nucleotide, $\mathrm{Y}$ is pyrimidine, $\mathrm{R}$ is purine, and $\mathrm{A}$ is the branch point adenosine) is very loosely defined (Burge et al. 1999). In fact, upon a closer inspection of the cryptic branch sites that were relatively efficiently activated, we found that virtually any sequences could serve as branch sites so long as they were sufficiently close to the $3^{\prime}$ splice site and the branch point nucleotide remained an adenosine. For instance, the three most frequently used cryptic sites in the adenovirus pre-mRNA were $<40 \mathrm{nt}$ upstream of the 3' splice site, and they have the following sequences: AUGU CAU, UGAUGAU, and CCUUGAU, where the $3^{\prime}$-most adenosines are the branch points. One advantage of having loose branch sites (or many cryptic branch sites) is probably to ensure that splicing does take place even when the authentic branch site is mutated. This feature is clearly advantageous to cell survival.

It is interesting that higher-order complexes appeared when the lonely branch point adenosine (in pre-mRNA free of cryptic branch sites) was $2^{\prime}$-O-methylated. Given that they migrated slower than functional splicing complexes $\mathrm{B}$ and C (functional spliceosome), the higher-order complexes appeared to be larger than and distinct from the functional spliceosome, suggesting that these complexes are nonfunctional. On the other hand, it appeared that only U2, U5, and U6 were in these large complexes; U1 and U4 were not present. It is well established that the newly formed spliceosome (or a functionally inactive spliceosome), which contains all five snRNAs, undergoes conformational changes, releasing $\mathrm{U} 1$ and $\mathrm{U} 4$ and giving rise to functionally active spliceosome (complexes B and C) containing only U2, U5, and U6 (Nilsen 1994). Our results thus suggest that conformational changes did occur; how- ever, 2'-O-methylation at the branch point nucleotide affected the chemical reaction-the first transesterification reaction. The failure to initiate the first step of splicing might, in turn, trigger further binding with other unidentified proteins, resulting in the larger complexes. Alternatively, the blockage of the first step of splicing might induce some conformational changes, giving rise to the more slowly migrating complexes. Further investigation is necessary to clarify the mechanism.

Our experiments show that an artificial box C/D RNA, when injected into Xenopus oocytes, can introduce 2'-Omethylation into pre-mRNA present in the nucleoplasm. While it is possible that the artificial guide RNA might unnaturally travel to the nucleoplasm after cytoplasmic injection (due to excessive injection), resulting in premRNA modification in this nuclear subcompartment, we believe that this possibility is unlikely given that we injected only a moderate amount of guide RNA $(\sim 20 \mathrm{ng}$ per oocyte). In fact, by primer-extension criterion, we detected a similar level (no more than twofold) of artificial guide RNA in the nucleus when compared with the levels of endogenous guide RNA species (data not shown). Our present result is consistent with the previous data obtained from similar experiments conducted in S. cerevisiae (Zhao and $\mathrm{Yu}$ 2008) and in mammalian cells (although the modification efficiency is lower in mammalian cells) (Cavaille et al. 1996; Semenov et al. 2008). Collectively, these experiments suggest that the modification machinery (snoRNA/snoRNP) is, indeed, naturally present in the nucleoplasm, as well as in the other two nuclear subcompartments, nucleoli and Cajal bodies, to which rRNA and snRNA (two natural substrates) are localized, respectively (Smith and Steitz 1997; Kiss 2002; Yu et al. 2005). Indeed, there are at least two reports that suggest the nucleoplasmic localization of snoRNA/snoRNP (Liang et al. 2002; Zhao et al. 2002). Furthermore, the Gall group has recently demonstrated that Cajal bodies are not required for snRNA modifications, implying that snRNA modification can occur in the nucleoplasm as well (Deryusheva and Gall 2009). Taken together, experimental data gathered thus far strongly suggest that the modification machinery is dispersed throughout the nucleoplasm (including the nucleoli and Cajal bodies), and that several different types of nucleoplasmic RNA can be targeted for modification.

Our RNA-guided RNA modification approach offers a unique tool for RNA research. Although the branch point may not be the ideal target for blocking pre-mRNA splicing in vertebrate cells (there are a number of cryptic branch sites in vertebrate pre-mRNAs), some other important sites (for example, the $5^{\prime}$ and $3^{\prime}$ splice sites) may still be good targets for splicing regulation. On the other hand, given that $2^{\prime}$-O-methylation can be site-specifically introduced into pre-mRNA and many other RNAs, this technique may potentially be useful for in vivo probing of RNA structure and sequence accessibility. 


\section{MATERIALS AND METHODS}

\section{Construction of artificial box C/D RNA}

Artificial box C/D RNAs were constructed according to the sequence of U25, an authentic human box C/D RNA of $97 \mathrm{nt}$ (Tycowski et al. 1996). Two overlapping primers, one corresponding to the HindIII site and first 56 nt of U25 (with the guide sequence between box $\mathrm{C}$ and $\mathrm{D}^{\prime}$ changed to target the branch point adenosine of adenovirus pre-mRNA), and the other being complementary to the BamHI site and nucleotides 41-97 of U25, were annealed, and extended by PCR. The DNA product was then inserted into the pcDNA3.1(+) vector (Invitrogen) at the HindIII and BamHI sites. Upon linearization with BamHI, in vitro T7 transcription was carried out to generate an artificial box $\mathrm{C} / \mathrm{D}$ guide RNA, targeting the branch point adenosine of adenovirus pre-mRNA.

\section{Xenopus oocyte microinjection and pre-mRNA splicing}

Microinjection was performed essentially as previously described (Yu et al. 1998; Zhao and Yu 2004). Briefly, $46 \mathrm{~nL}$ of $2 \mathrm{mg} / \mathrm{mL}$ antisense U2 DNA oligonucleotide (complementary to nucleotides 28-42) together with $500 \mathrm{ng} / \mu \mathrm{L}$ mature guide RNA targeting the branch point or a random site (as a control) were injected into the cytoplasm of Xenopus oocytes. After the endogenous U2 was completely degraded by endogenous RNase $\mathrm{H}$ activity ( $>4 \mathrm{~h}), 9 \mathrm{~nL}$ of standard adenovirus splicing substrate, containing a single ${ }^{32} \mathrm{P}$ at the branch point $(500,000 \mathrm{cpm} / \mu \mathrm{L})$, were directly injected into the nucleus of oocytes. (For mapping cryptic branch points [see below], we injected, instead of the singly radiolabeled pre-mRNA, $\sim 50 \mathrm{ng}$ of unlabeled pre-mRNA or a mixture of T7 polymerase and T7 plasmid containing the pre-mRNA sequence [see below].) After an overnight incubation, $40 \mathrm{~nL}$ of $50 \mathrm{ng} / \mu \mathrm{L}$ synthetic $\mathrm{U} 2$ (in vitro transcribed) were injected into the cytoplasm of the oocytes. Following an overnight $(16 \mathrm{~h})$ reconstitution, nuclei were isolated and treated with proteinase $\mathrm{K}$, and nuclear RNA was extracted with PCA and precipitated with ethanol. The recovered RNA was loaded on a $7 \%$ polyacrylamide- $8 \mathrm{M}$ urea gel (acrylamide: bis = 19:1; EM Science), and radiolabeled pre-mRNA and the lariat intron product were visualized after autoradiography.

For assessing 2'-O-methylation at the branch point (see below), pre-mRNA and the lariat intron product were excised from the gel, eluted, and recovered by PCA extraction and ethanol precipitation.

\section{2'-O-Methylation assay}

Recovered lariat intron was debranched according to published procedures (Ruskin and Green 1985, 1990). Briefly, the reaction mixture, containing $8 \mu \mathrm{L}$ of RNA, $2 \mu \mathrm{L}$ of $0.1 \mathrm{M}$ EDTA ( $\mathrm{pH} 8.0$ ), and $15 \mu \mathrm{L}$ of HeLa cell S100 extract, was incubated for 30-60 min at $30^{\circ}$. The reaction was terminated by the addition of $75 \mu \mathrm{L}$ of water, $100 \mu \mathrm{L}$ of $2 \times$ proteinase $\mathrm{K}$ buffer $(200 \mathrm{mM}$ Tris- $\mathrm{HCl}$ at $\mathrm{pH}$ 7.5, $300 \mathrm{mM} \mathrm{NaCl}, 2 \%$ sodium dodecyl sulfate [SDS], $25 \mathrm{mM}$ EDTA), and $10 \mu \mathrm{L}$ of $10 \mathrm{mg} / \mathrm{mL}$ proteinase $\mathrm{K}$. Upon incubation for $30 \mathrm{~min}$ at $55^{\circ}$, RNA was recovered by PCA extraction and ethanol precipitation.

The debranched intron and previously isolated unspliced premRNA were then digested with nuclease P1 (at a final concen- tration of $200 \mu \mathrm{g} / \mathrm{mL}$ in $3 \mu \mathrm{L}$ of sodium acetate solution with a $\mathrm{pH}$ of 5.2) for $1 \mathrm{~h}$ at $37^{\circ} \mathrm{C}$. The digested samples were dotted on TLC PEI plates (EM Science) and chromatographed in the $\mathrm{HCl}: \mathrm{H}_{2} \mathrm{O}$ :isopropanol $(15: 15: 70[\mathrm{v} / \mathrm{v} / \mathrm{v}])$ solution for $\sim 6-7 \mathrm{~h}$. $\left[{ }^{32} \mathrm{P}\right] \mathrm{A}$ and $2^{\prime}-\mathrm{O}$-methylated $\left[{ }^{32} \mathrm{P}\right] \mathrm{A}$ (branch point) were separated and visualized by autoradiography.

\section{Mapping cryptic branch points by primer extension}

Xenopus oocyte nuclear RNA, containing spliced lariat products (see above), was used for primer-extension analysis, as previously described. The primer (5'-CTGTGGAAAAAAAAGGGA-3') was complementary to the last $18 \mathrm{nt}$ of the adenovirus pre-mRNA intron. The extension products were analyzed, in parallel with an adenovirus pre-mRNA sequence ladder, on a $7 \%$ polyacrylamide$8 \mathrm{M}$ urea gel (acrylamide: bis = 19:1; EM Science).

The mapping identified several potential cryptic branch point adenosines, with $\mathrm{A}_{-6}$ (6 nt upstream of the authentic branch point) being the strongest. Three of the sites, corresponding to $\mathrm{A}_{-6}, \mathrm{~A}_{-11}, \mathrm{~A}_{-14}$ (relative to the authentic branch point) were mutated to guanine by the QuikChange site-directed mutagenesis kit. The mutant pre-mRNA thus generated was termed "premRNA free of cryptic branch sites" (see the text).

\section{pre-mRNA splicing in Xenopus oocytes by injecting a T7 plasmid coding for adenovirus pre-mRNA}

Forty-six nanoliters of $2 \mathrm{mg} / \mathrm{mL}$ antisense U2 DNA oligonucleotide (complementary to nucleotides 28-42) together with $500 \mathrm{ng} / \mu \mathrm{L}$ box C/D guide RNA targeting the branch point or a random site were injected into the cytoplasm of Xenopus oocytes. After the endogenous $\mathrm{U} 2$ was completely degraded by endogenous RNase $\mathrm{H}$ activity ( $>4 \mathrm{~h}$ ), $9 \mathrm{~nL}$ of $200 \mathrm{ng} / \mu \mathrm{L}$ T7-adenovirus pre-mRNA plasmid were directly injected into the nuclei of oocytes. Forty nanoliters of $50 \mathrm{ng} / \mu \mathrm{L}$ rescuing $\mathrm{U} 2$ snRNA (in vitro transcribed) was injected into the cytoplasm of the oocytes. Following an overnight $(16 \mathrm{~h})$ reconstitution, nuclei were isolated and treated with proteinase K, and nuclear RNA was extracted with PCA and then precipitated with ethanol. The recovered RNA was loaded on a $7 \%$ polyacrylamide- $8 \mathrm{M}$ urea gel (acrylamide: bis = 19:1; EM Science). Standard Northern blotting was used to detect premRNA and lariat intron product. The probe used here was identical to that used for primer extension (see above).

\section{Analysis of splicing complexes by native gel electrophoresis}

Spliceosome assembly was carried out according to previous reports (Konarska 1989; Yu et al. 1998). Briefly, $46 \mathrm{~nL}$ of $2 \mathrm{mg} / \mathrm{mL}$ antisense U2 DNA oligonucleotide (complementary to nucleotides 28-42) together with $500 \mathrm{ng} / \mu \mathrm{L}$ box $\mathrm{C} / \mathrm{D}$ guide $\mathrm{RNA}$ targeting the branch point or a random site were injected into the cytoplasm of Xenopus oocytes. Four hours later, $9 \mathrm{~nL}$ of radiolabeled adenovirus splicing substrate $(\sim 500,000 \mathrm{cpm} / \mu \mathrm{L})$ were directly injected into the oocyte nucleus. After an overnight incubation, $9 \mathrm{~nL}$ of $50 \mathrm{ng} / \mu \mathrm{L}$ rescuing $\mathrm{U} 2$ (in vitro transcribed) were injected into the oocyte nucleus. Ten minutes later, nuclei were isolated and broken by pipetting up and down several times in $10 \mu \mathrm{L}$ of loading dye containing $9 \mathrm{mM}$ HEPES ( $\mathrm{pH}$ 7.9), 22.5 $\mathrm{mM} \mathrm{KCl}, 0.09 \mathrm{mM}$ EDTA, $0.22 \mathrm{mM}$ DTT, and $1 \mathrm{mg} / \mathrm{mL}$ heparin. 
The samples were then loaded on a $4 \%$ polyacrylamide native gel (acrylamide: bis $=80: 1$ ). The splicing complexes were visualized by autoradiography.

To check for snRNAs in the complexes, slow-migrating complexes were excised, RNAs were recovered, and RT-PCR was performed with snRNA-specific primers.

\section{ACKNOWLEDGMENTS}

We thank the members of the Yu laboratory for valuable discussions. This work was supported by grant GM62937 from the National Institutes of Health.

Received December 21, 2009; accepted February 10, 2010.

\section{REFERENCES}

Altafaj X, Joux N, Ronjat M, De Waard M. 2006. Oocyte expression with injection of purified T7 RNA polymerase. Methods Mol Biol 322: 55-67.

Burge CB, Tuschl T, Sharp PA. 1999. Splicing of precursors to mRNAs by the spliceosome. In The RNA world (ed. RF Gesteland et al.), pp. 525-560. Cold Spring Harbor Laboratory Press, Cold Spring Harbor, NY.

Cavaille J, Nicoloso M, Bachellerie JP. 1996. Targeted ribose methylation of RNA in vivo directed by tailored antisense RNA guides. Nature 383: 732-735.

Darzacq X, Jady BE, Verheggen C, Kiss AM, Bertrand E, Kiss T. 2002. Cajal body-specific small nuclear RNAs: A novel class of 2'-Omethylation and pseudouridylation guide RNAs. EMBO J 21: 2746-2756.

Deryusheva S, Gall JG. 2009. Small Cajal body-specific RNAs (scaRNAs) of Drosophila function in the absence of Cajal bodies. Mol Biol Cell 20: 5250-5259.

Kiss T. 2002. Small nucleolar RNAs: An abundant group of noncoding RNAs with diverse cellular functions. Cell 109: 145-148.

Kiss-Laszlo Z, Henry Y, Bachellerie JP, Caizergues-Ferrer M, Kiss T. 1996. Site-specific ribose methylation of preribosomal RNA: A novel function for small nucleolar RNAs. Cell 85: 1077-1088.

Konarska MM. 1989. Analysis of splicing complexes and small nuclear ribonucleoprotein particles by native gel electrophoresis. Methods Enzymol 180: 442-453.

Liang XH, Xu YX, Michaeli S. 2002. The spliced leader-associated RNA is a trypanosome-specific sn(o) RNA that has the potential to guide pseudouridine formation on the SL RNA. RNA 8: 237-246.

Liu B, Fournier MJ. 2004. Interference probing of rRNA with snoRNPs: A novel approach for functional mapping of RNA in vivo. RNA 10: 1130-1141.

Liu B, Ni J, Fournier MJ. 2001. Probing RNA in vivo with methylation guide small nucleolar RNAs. Methods 23: 276-286.

Liu B, Liang XH, Piekna-Przybylska D, Liu Q, Fournier MJ. 2008. Mis-targeted methylation in rRNA can severely impair ribosome synthesis and activity. RNA Biol 5: 249-254.

Newby MI, Greenbaum NL. 2002. Sculpting of the spliceosomal branch site recognition motif by a conserved pseudouridine. Nat Struct Biol 9: 958-965.
Ni J, Samarsky DA, Liu B, Ferbeyre G, Cedergren R, Fournier MJ. 1997. SnoRNAs as tools for RNA cleavage and modification. Nucleic Acids Symp Ser 1997: 61-63.

Nilsen TW. 1994. RNA-RNA interactions in the spliceosome: Unraveling the ties that bind. Cell 78: 1-4.

Parker R, Siliciano PG, Guthrie C. 1987. Recognition of the TACTAAC box during mRNA splicing in yeast involves base pairing to the U2-like snRNA. Cell 49: 229-239.

Query CC, Moore MJ, Sharp PA. 1994. Branch nucleophile selection in pre-mRNA splicing: Evidence for the bulged duplex model. Genes \& Dev 8: 587-597.

Ruskin B, Green MR. 1985. An RNA processing activity that debranches RNA lariats. Science 229: 135-140.

Ruskin B, Green MR. 1990. RNA lariat debranching enzyme as tool for analyzing RNA structure. Methods Enzymol 181: 180-188.

Ruskin B, Krainer AR, Maniatis T, Green MR. 1984. Excision of an intact intron as a novel lariat structure during pre-mRNA splicing in vitro. Cell 38: 317-331.

Semenov DV, Vratskih OV, Kuligina EV, Richter VA. 2008. Splicing by exon exclusion impaired by artificial box C/D RNA targeted to branch-point adenosine. Ann N Y Acad Sci 1137: 119-124.

Smith CM, Steitz JA. 1997. Sno storm in the nucleolus: New roles for myriad small RNPs. Cell 89: 669-672.

Staley JP, Guthrie C. 1998. Mechanical devices of the spliceosome: Motors, clocks, springs, and things. Cell 92: 315-326.

Tycowski KT, Smith CM, Shu MD, Steitz JA. 1996. A small nucleolar RNA requirement for site-specific ribose methylation of rRNA in Xenopus. Proc Natl Acad Sci 93: 14480-14485.

Tycowski KT, Shu MD, Kukoyi A, Steitz JA. 2009. A conserved WD40 protein binds the Cajal body localization signal of scaRNP particles. Mol Cell 34: 47-57.

Wu J, Manley JL. 1989. Mammalian pre-mRNA branch site selection by U2 snRNP involves base pairing. Genes \& Dev 3: 1553-1561.

Yu YT, Shu MD, Steitz JA. 1998. Modifications of U2 snRNA are required for snRNP assembly and pre-mRNA splicing. EMBO J 17: 5783-5795.

Yu YT, Scharl EC, Smith CM, Steitz JA. 1999. The growing world of small nuclear ribonucleoproteins. In The RNA world (ed. RF Gesteland et al.), pp. 487-524. Cold Spring Harbor Laboratory Press, Cold Spring Harbor, NY.

Yu YT, Shu MD, Narayanan A, Terns RM, Terns MP, Steitz JA. 2001. Internal modification of U2 small nuclear (sn)RNA occurs in nucleoli of Xenopus oocytes. J Cell Biol 152: 1279-1288.

Yu YT, Terns RM, Terns MP. 2005. Mechanisms and functions of RNA-guided RNA modification. In Fine-tuning of RNA functions by modification and editing (ed. H Grosjean), pp. 223-262. Springer, New York.

Zhao X, Yu YT. 2004. Pseudouridines in and near the branch site recognition region of U2 snRNA are required for snRNP biogenesis and pre-mRNA splicing in Xenopus oocytes. RNA 10: 681-690.

Zhao X, Yu YT. 2008. Targeted pre-mRNA modification for gene silencing and regulation. Nat Methods 5: 95-100.

Zhao X, Li ZH, Terns RM, Terns MP, Yu YT. 2002. An H/ACA guide RNA directs U2 pseudouridylation at two different sites in the branchpoint recognition region in Xenopus oocytes. RNA 8: 15151525.

Zhuang Y, Weiner AM. 1989. A compensatory base change in human U2 snRNA can suppress a branch site mutation. Genes \& Dev 3: 1545-1552. 

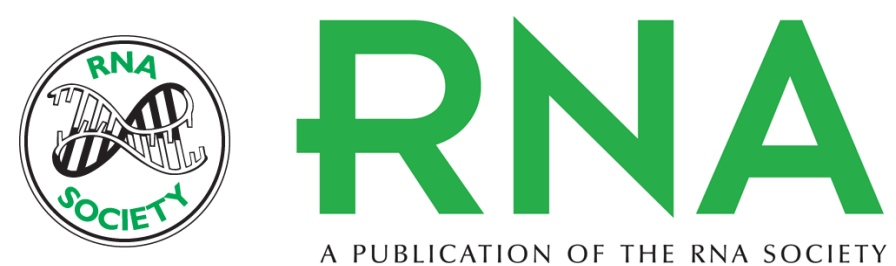

A PUBLICATION OF THE RNA SOCIETY

\section{Regulation of pre-mRNA splicing in Xenopus oocytes by targeted 2'-O -methylation}

JuNhui Ge, Huimin Liu and Yi-Tao Yu

RNA 2010 16: 1078-1085 originally published online March 26, 2010

Access the most recent version at doi:10.1261/rna.2060210

$\begin{array}{ll}\text { References } & \begin{array}{l}\text { This article cites } 31 \text { articles, } 13 \text { of which can be accessed free at: } \\ \text { http://rnajournal.cshlp.org/content/16/5/1078.full.html\#ref-list-1 }\end{array}\end{array}$

License

Email Alerting Receive free email alerts when new articles cite this article - sign up in the box at the Service top right corner of the article or click here.

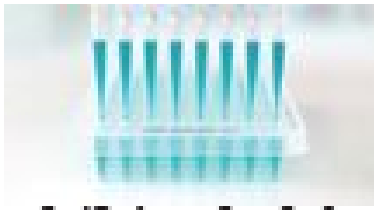

Providing Precise Solutions for your research.

To subscribe to RNA go to:

http://rnajournal.cshlp.org/subscriptions 